\title{
Attention-deficit/hyperactivity disorder (ADHD) symptoms and academic entrepreneurial preference: is there an association?
}

\author{
Ivonne Canits • Indy Bernoster • Jinia Mukerjee • \\ Jean Bonnet • Ugo Rizzo • Mario Rosique-Blasco
}

Accepted: 11 December 2017 /Published online: 1 May 2018

(C) The Author(s) 2018

\begin{abstract}
Although commercialization of research activities has drawn some research attention, more studies are warranted to clearly understand the drivers behind academic entrepreneurship. The present paper investigates the association between attention-deficit/hyperactivity disorder (ADHD) symptoms and academic entrepreneurial preference. ADHD symptoms have typically been associated with impaired occupational functioning among wage employees. Recent studies, however, indicate that the same symptoms of ADHD that are a liability for wage employees may work out differently for
\end{abstract}

I. Canits $\cdot$ I. Bernoster $(\bowtie)$

Department of Applied Economics, Erasmus School of

Economics, Erasmus University Rotterdam, Rotterdam,

The Netherlands

e-mail: bernoster@ese.eur.nl

I. Canits $\cdot$ I. Bernoster

Erasmus University Rotterdam Institute for Behavior and Biology (EURIBEB), Erasmus University Rotterdam, Rotterdam,

The Netherlands

J. Mukerjee

Montpellier Business School, Montpellier Research in

Management, Montpellier, France

\section{J. Bonnet}

Department of Economics and Management, Normandie Univ, CNRS, CREM, Caen, France

\section{U. Rizzo}

Department of Economics and Management, University of

Ferrara, Ferrara, Italy

M. Rosique-Blasco

Polytechnic University of Cartagena, Cartagena, Spain entrepreneurs. Building on previous studies that link ADHD symptoms to entrepreneurship, and using the theoretical lens of person-environment fit, we hypothesize that ADHD symptoms (at the so-called subclinical level) are associated with academic entrepreneurial preference. Results of our data from academic researchers in France, Spain, and Italy $(N=534)$ show that there is a negative association between attention-deficit symptoms and academic entrepreneurial preference. However, there is no link between hyperactivity symptoms and academic entrepreneurial preference.

Keywords Academic entrepreneurial preference . Attention-deficit symptoms · Hyperactivity symptoms

JEL classifications $\mathrm{I} 10 \cdot \mathrm{L} 26$

\section{Introduction}

Due to the increasing involvement of universities in entrepreneurial activities, interest in the study of academic entrepreneurship has started to gain valence in the recent years (Klofsten and Jones-Evans 2000; Zucker et al. 2002). Although variously defined in the literature (Klofsten and Jones-Evans 2000; Guerrero and Urbano 2014), we define academic entrepreneurship as being involved in the commercialization of research output, for instance, in the form of creating an organization (academic spin-off) or patenting. Some studies have attempted to determine the drivers of academic entrepreneurship. For example, the intention to engage in 
academic entrepreneurship has been shown to be directly influenced by perceptions of desirability and feasibility of entrepreneurial activities, and only indirectly by university entrepreneurial climate and the perceived fit between the academic department's values and entrepreneurship behavior (Llano 2010). Additionally, attitudes and perceived behavior control have been found to be some of the important psychological determinants of academic entrepreneurial engagement (Goethner et al. 2012). However, more studies are warranted to clearly understand the drivers behind academic entrepreneurship, particularly drivers pertaining to individual characteristics.

The individual characteristics that make an entrepreneur have been a matter of significant interest in both research (Shane 2003; Parker 2009; Gorgievski and Stephan 2016) and popular press (The Economist 2012). Studies have shown that individuals who engage in entrepreneurship score high in an array of characteristics such as energy level, persistence (Neider 1987), selfefficacy, openness to new experience, need for achievement, entrepreneurial orientation (characterized by autonomy, innovativeness, risk-taking, proactivity, and competitive aggressiveness) (Frese and Gielnik 2014), and psychological resilience (Markman and Baron 2003). Recently, the entrepreneurship literature has started showing interest in individual characteristics associated with psychiatric disorders (Mathieu and St-Jean 2013; Johnson et al. 2015). One such disorder that has grabbed scholarly attention is attention-deficit/hyperactivity disorder (ADHD) (Verheul et al. 2015; Thurik et al. 2016; Wiklund et al. 2016a, b). This relatively common developmental disorder (Egger and Angold 2006) is characterized by attention-deficit, hyperactivity, and impulsivity (Barkley 1997) and typically starts in childhood. Although its prevalence generally declines with age among clinical samples (Biederman et al. 2000), a large-scale study in ten countries revealed its prevalence to be between 3 and 5\% in adults (Fayyad et al. 2007).

Due to its primary symptoms and the associated comorbidities with depression, substance use, and anxiety disorders (Barkley et al. 2010), ADHD is often related to negative consequences within the wage-employed work context such as suboptimal job performance, unemployment, and a higher incidence of absence days (Secnik et al. 2005; Kessler et al. 2009). Popular press, however, suggests that within the entrepreneurial context, those with ADHD may actually benefit from their symptoms, and has gone so far as to call ADHD an "entrepreneurfriendly affliction" (The Economist 2012). Examples include entrepreneurs David Neeleman (founder of JetBlue Airlines), Paul Orfalea (founder of Kinko's), and Richard Branson (Virgin group), who claim that their high levels of energy and risky behavior pertaining to their ADHD symptoms give them the ability to break through business routines, to envision and create new realities: the ingredients of an entrepreneur (The Economist 2012). According to the person-environment fit (P-E fit) literature, individuals engage in environments and work tasks that are congruent to their personal traits (Kristof-Brown et al. 2005). While individuals with higher levels of ADHD symptoms do not fit well in a wage-paid work environment, these same symptoms often attract them to entrepreneurship, which is "the process of discovery, evaluation, and exploitation of opportunities" (Shane and Venkataraman 2000, p. 218), usually characterized by high risk, less routines, and more independence (Mannuzza et al. 1993), with ample room for novelty seeking and innovation (Anckarsäter et al. 2006).

Indeed, several recent studies show a positive association between ADHD symptoms and different aspects of entrepreneurship-like entrepreneurial choice, intention, and behavior. For example, Verheul et al. (2015) showed that students with higher selfreported levels of ADHD are more likely to have entrepreneurial intentions. This association was partly explained by risk propensity as a mediator. Among entrepreneurs diagnosed with ADHD, impulsivity mediated the relation between ADHD symptoms and entrepreneurial actions like proactivity and risk-taking (Wiklund et al. 2016a). In the same line, a study conducted on a sample of small business owners revealed a positive association between ADHD symptoms and entrepreneurial orientation measured using risk aversion, innovativeness, and proactivity (Thurik et al. 2016). While all these studies focused on ADHD-like behavior, a recent study by Lerner et al. (2018) shows that there is also a positive association between the clinically diagnosed condition of ADHD and entrepreneurial intention and action.

Research that has made a finer distinction between the attention-deficit and hyperactivity symptoms of ADHD shows that there is a positive link between the hyperactivity symptoms and rates of self-employment, but a negative one between the attention-deficit symptoms and rate of self-employment (Verheul et al. 2016). These are precisely the hypotheses that we aim to test in the present paper, albeit in the context of academic entrepreneurship. 
The above studies thus seem to suggest an association between ADHD symptoms and entrepreneurial measures in different samples: notably among students, a general adult sample, and small business owners. However, in the present paper, we investigate the association of ADHD symptoms with academic entrepreneurial preference among academic researchers in an attempt to connect to the literature on academic entrepreneurship. Specifically, we hypothesize that hyperactivity symptoms drive the preference for academic entrepreneurial activities, while attention-deficit symptoms hamper the same. We investigate these hypotheses using a sample of academic researchers in France, Spain, and Italy $(N=534)$.

We do so in view of the importance of academic entrepreneurship and the previously discussed recent promising results on the relation between ADHD symptoms and different aspects of entrepreneurship (see Antshel 2017 for a review). The second reason that motivates our study is that in relatively homogeneous groups, the influence of personality traits on preferences may be corrected for context. Preferences (such as for entrepreneurial activities) are not just connected to someone's personal traits (as represented by measurements using psychological disorder scales) but also to what degree, there is a fit between one's personality and the context (such as the work environment) (Kristof 1996). This leads to the obvious observation that the relation between personal traits and preferences can be blurred by context. Choosing a homogeneous context may then become a necessary condition for identifying this relation. This is precisely what we do in the present paper by confining ourselves to the academic environment. The third reason is the recent call for research to better understand which specific industry and context are related to entrepreneurship outcomes for adults with ADHD (Antshel 2017) as environmental context may be a salient predictor of ADHD symptoms (Crea et al. 2014). Moreover, we believe that academics with ADHD symptoms can be seen as a special subgroup within the ADHD population, as high intelligence is typically associated with a better prognosis and coping for individuals with ADHD symptoms (Mahone et al. 2002; Biederman et al. 2006). Nevertheless, hyperactivity may also, for academics, explain a drive to move beyond their normally accepted duties and pursue a riskier path of academic entrepreneurship.

Our study aims to make three contributions. Firstly, investigating the relation between ADHD symptoms and academic entrepreneurial preference enhances our understanding of entrepreneurial activities in this specific context. We chose this highly relevant context because of a rising trend among universities internationally to promote and foster academic entrepreneurship. Exploring the association between ADHD symptoms and academic entrepreneurial preference may add to our knowledge of the drivers of academic entrepreneurship, which is of both theoretical and practical value. Secondly, it contributes to the nascent literature of psychological disorders (albeit at the subclinical level, i.e., not manifesting in the level of diagnosable clinical disorder) and its link to entrepreneurial preference and behavior. By doing so, it not only adds (in a general sense) to the large body of literature that attempts to answer the question: what makes an entrepreneur ${ }^{1}$ (Ripsas 1998; Burke et al. 2008), but also joins hands with the literature that tries to unravel the role of psychology in the development of a comprehensive view of entrepreneurship (Hisrich et al. 2007). Thirdly, and in complement to the previous general contribution to the literature of psychological disorders and different aspects of entrepreneurship, it has a more specific contribution related to the role of context. As explained before, choosing a homogeneous context may be a necessary condition for identifying the relation between different aspects of entrepreneurship (such as entrepreneurial intention) and personal traits (such as those measured using psychological disorder scales). This is precisely what we do in the present paper by confining ourselves to the academic environment. Taken together, our study aims to partially validate and extend prior research.

\section{Theoretical background}

\subsection{Person-environment fit}

The person-environment fit is defined by the extent to which the characteristics of an individual and that of his/ her environment match (Kristof 1996). The basic tenet of this theoretical approach is that of an interaction between the individual and his/her environmental context, such that neither the personal nor the environmental factors can provide a "stand-alone" explanation of human behavior (Edwards and Cooper 1990; Edwards et al. 2006). The notion of the "environment" has also been extended to the work/occupational context. Thus,

\footnotetext{
${ }^{1}$ This literature started with Blanchflower and Oswald (1998).
} 
more specifically, the person-organization fit (Kristof 1996) refers to the congruence between a person and his organizational values, and the person-job fit (Cable and DeRue 2002) refers to the congruence between an individual's characteristics and his/her job requirements. The implication of the broad theoretical perspective of $\mathrm{P}-\mathrm{E}$ fit is far reaching, both for individuals and the organization. For example, congruence between an individual and the organization has been shown to be associated with greater organizational commitment, better job performance, higher job involvement, improved employee attitudes, lower turnover, to name a few (O’Reilly et al. 1991).

In the entrepreneurship domain, scholars have argued that closer is the congruence between an entrepreneur's personal characteristics and the demands of being an entrepreneur, better is the person-entrepreneur fit and, consequently, the likelihood of entrepreneurial success (Markman and Baron 2003). In other words, entrepreneurs possess distinct individual characteristics (that differ from non-entrepreneurs), which make them fit for the entrepreneurial journey and its success. However, not all entrepreneurial journeys are the same; the context has a vital role to play in this regard. Thus, studying a particular context such as academic entrepreneurship can effectively contribute to the literature on context specificity in entrepreneurship.

It should be kept in mind that in the case of ADHD, "the terms hyperactive or attention-deficit are contextdependent by definition" (Rosenberg 2006, p. 419); this means that attention-deficit and hyperactivity symptoms for an individual would vary from high to low, depending on the environmental context, considering that behavioral traits, or even psychopathology, change with situation. The diagnostic criteria for ADHD (American Psychiatric Association (APA) 2013) clearly point to this context specificity for measuring and labeling behaviors as dysfunctional (Lasky et al. 2016). In the occupational context, work environmental norms as well as the work itself dictates which behavior is acceptable. For example, welldefined, repetitive, and/or routine-based tasks are often perceived by people with ADHD to be boring, not intrinsically motivating and hence effortful (Lasky et al. 2016). Such work context and tasks are thus often incompatible with symptoms of attention-deficit or hyperactivity and may even intensify these symptoms.

The entrepreneurship path, on the other hand, is often marred with uncertainty and risk. Consequently, it demands a high tolerance for instability and risk, proactiveness, flexibility in routines, and the ability to engage in novel and innovative tasks (Shane and Venkataraman 2000; Baron 2008). Symptoms of ADHD-like impulsivity make closely supervised structured work difficult, but favor the path of risky, uncertain self-employment; attention problems make working on structured tasks hard but favor fastpaced, non-routine, intrinsically motivating tasks, which have a dash of creativity (Verheul et al. 2015). Not surprisingly, individuals with ADHD report that a highly stimulating environment characterized by fast-paced, multitasking, intrinsically interesting tasks with high levels of novelty, challenge, and stress provides them with the best P-E fit and helps them cope effectively with ADHD symptoms (Lasky et al. 2016). Entrepreneurship and its demands often match the criteria of such a highly stimulating work environment. Indeed, in his review of entrepreneurship and ADHD, Antshel (2017) argues that individuals with ADHD symptoms often tend to find entrepreneurship more suitable (hence attractive) as an occupation, given that their personal characteristics "fit" with the demands of entrepreneurship.

\subsection{ADHD symptoms and academic entrepreneurial preference}

There is a growing research interest to uncover the brighter side of ADHD symptoms in the entrepreneurial context (Thurik et al. 2016; Wiklund et al. 2016a, b). Rather than viewing ADHD symptoms as a deficit for individuals in the work context, this stream of research has empirically shown that there is a positive association between several aspects of entrepreneurship and both overall ADHD symptoms and hyperactivity symptoms (for a review see Antshel 2017).

Despite what we already know about this association, there are still questions that remain unanswered and warrant investigation (Antshel 2017). One intriguing question is that of the role of entrepreneurial context in this association between symptoms of ADHD and the different aspects of entrepreneurship. This question can only be answered when the issue of context is corrected for, by confining the investigation to a relatively homogenous group. In the present paper, we therefore investigate the association between ADHD and academic entrepreneurial preference in the specific context of academic researchers. 
Over the last few decades, universities have acquired a new role, in complement to that of providing research and transmission of knowledge: the role of providers of new technology and business ventures in order to be a force in the economic development (Laukkanen 2003). The public authorities are also increasingly paying attention to the economic valorization of research activities and its commercial exploitation through patenting, consultations with private sector researchers, and private/public collaborations (Shane 2004; Vincett 2010). Rather than being "isolated island of knowledge" (Klofsten and JonesEvans 2000, p. 299), universities and the academics therein have embarked on more risky forms of entrepreneurial activity, like forming start-up companies around a university-developed technology or licensing to small private firms (Powers and McDougall 2005).

Research indicates that a variety of environmental and individual factors act as drivers of academic entrepreneurial activities. For example, industry resource funding, number of patents produced by the university, and venture capital munificence in the universities' geographical locations (Powers and McDougall 2005) have been shown to be some of the important environmental drivers. On the other hand, previous industrial experience (Cooper and Dunkelberg 1986), past self-employment, exposure to small business management (Jones-Evans 1992), personal need for achievement, the desire for independence, an internal locus of control (Roberts 1991), and perceptions of desirability and feasibility of entrepreneurial activities (Llano 2010) are some of the individual factors associated with eventual preference and involvement in academic entrepreneurship.

As in the case of entrepreneurship in general, where the individual personality factors indeed matter (Markman and Baron 2003), we conjecture that academic entrepreneurial preference and activities would also be influenced by one's personality. Our motivation to investigate this becomes even more compelling when we notice that given the same environmental factors and resources, such as the industry $R \& D$ revenue, the importance attached to patenting by the universities as well as universities' patent portfolio, presence of venture capitalists in the region, etcetera (Powers and McDougall 2005), some academics engage in entrepreneurial activities while others do not. We thus hypothesize that academic researchers with hyperactivity symptoms would prefer engaging in entrepreneurial activities in complement to their usual work duties.
Hypothesis 1: There is a positive link between hyperactivity symptoms and academic entrepreneurial preference.

Based on earlier research which shows a negative association between attention-deficit and entrepreneurship (Verheul et al. 2016), we also believe that attention-deficit symptoms would deter one's preference for academic entrepreneurship, as focusing one's attention to the entrepreneurial activity on top of the normal job duties would be overly taxing for such individuals.

Hypothesis 2: There is a negative link between attention-deficit symptoms and academic entrepreneurial preference.

\section{Method}

\subsection{Data and sample}

A French research team ${ }^{2}$ collected data using a survey with the aim to investigate why the creation of firms can be a viable professional orientation for academic researchers and administrative/ technical personnel. The survey was replicated in Spain (Polytechnic University of Cartagena) and in Italy (University of Ferrara). ${ }^{3}$ The total sample consisted of academic researchers $(N=534)$ and administrative/technical personnel $(N=232)$. To test our hypotheses, we used the academic researcher group as our sample. The division among countries is as follows: France $(N=98)$, Spain $(N=169)$, and Italy $(N=267)$. Participants received a 46-item questionnaire ${ }^{4}$ which took approximately $20 \mathrm{~min}$ to fill in.

\footnotetext{
2 Thomas Brau and Jean Bonnet of University of Caen Normandy. Many questions of the survey were adapted from the doctoral thesis of Thomas Brau (2009) on psychological characteristics of innovative entrepreneurs. The survey benefited from the contributions of Roy Thurik and Ingrid Verheul (Erasmus University Rotterdam), Domingo Garcia (University of Cartagena), Dominique Martin (University of Rennes 1), Marcus Dejardin and Julie Hermans (University of Namur), Alina Gomez (University Javeriana Cali), Esperanza Roman (Distrital University in Bogotá), and Haifa Naffaki (University of Caen).

${ }^{3}$ Data in Spain (Polytechnic University of Cartagena) was collected by Domingo Garcia and in Italy (University of Ferrara) by Ugo Rizzo.

${ }^{4}$ The questionnaires were translated in the appropriate language (French, Italian, and Spanish).
} 


\subsection{Measures}

\subsubsection{Dependent variables: academic entrepreneurial preference}

Using some questionnaire items, it was possible to create a general construct measuring a preference for academic entrepreneurial activities. These particular items were then split into two separate constructs: one construct measuring if there was a preference for commercialization of research results and the other construct related to the preference of possible consequences of commercialization. Both constructs are explained in detail below. These constructs are novel and not based on prior research. We are aware of the limitations of using such non-validated constructs and will discuss this in Section 6.

Academic entrepreneurial commercialization To measure academic entrepreneurial commercialization, the question "If the results of your research or the use of your abilities led to commercialization, under what form would you consider it?" was used. Participants chose their response from the following multiple options: (1) "The creation of a firm," (2) "The creation of a firm in the special legal setting of a young innovative firm," (3) "Patent registration and development by the use of licenses," (4) "Sell patents to firms which have interest in them," and (5) "Let others deal with the commercialization of the research results." This resulted in five binary variables, where the value 1 corresponds to choosing an option. Of these five options, the first four were interpreted as a positive preference towards commercialization of research results, while the fifth option was interpreted as a negative preference. In other words, the fifth variable was reversed. Academic entrepreneurial commercialization was then calculated by the sum of the five variables.

Personal attitude towards entrepreneurship We measured personal attitude towards entrepreneurship as a formative construct in order to span over several dimensions. We used six items which express the prospectively envisioned consequences of firm creation if the individual was to create his/her own firm. The items were "The creation of your own firm would personally give you the feeling of doing more for the wellbeing of others," "The creation of your own firm would personally lessen the abilities you have in your own professional field because the firm would keep you away from it" (reversed), "The creation of your own firm would personally enable you improve considerably your curriculum vitae," "The creation of your own firm would personally make you take the risk of an unwanted break in a promising career" (reversed), "The creation of your own firm would personally create relations with the structures of research development of your workplace," and "The creation of your own firm would personally bring you to be preoccupied by technical, commercial or other issues linked to your firm, during your free time" (reversed). All items were measured on a scale ranging from 0 to 100 , where higher scores indicated higher agreeableness. For each participant, the average of the scores on the items was used for analysis.

\subsubsection{Independent variable: ADHD symptoms}

ADHD symptoms were assessed using the six-item Adult ADHD Self-Report Scale v1.1 (ASRS v1.1): a short screening scale used for the general population (Kessler et al. 2005). This six-item screener has been proven to be effective in predicting adult ADHD. The items, rated on a 5 -point scale $(1=$ never, $5=$ very often), were averaged into two sub-dimensions: attentiondeficit and hyperactivity. The attention-deficit dimension was measured by four items: "How often have you had trouble wrapping up the final details of a project, once the challenging parts have been done?", "How often do you have difficulties getting things in order when you have to do a task that requires organization?", "How often do you have problems remembering appointments or obligations?", and "When you have a task that requires a lot of thought, how often do you avoid or delay getting started?." The hyperactivity dimension was measured by the remaining two items: "How often do you fidget or squirm with your hands and feet when you have to remain seated for a long time?" and "How often do you feel overly active and compelled to do things, as if you were driven by a motor?." Although this six-item screener is effective in predicting adult ADHD, the aspects of attention-deficit are probably better captured than those of hyperactivity due to the use of negative words (such as "trouble," "difficulties," "problems," and "avoid or delay") in the attention-deficit items; the hyperactivity items on the other hand do not have any negative words. Reliability scores measured by Cronbach's alpha were .64 and .50 , respectively. Although relatively low, these scores are 
still close to the lower bound of .63 as reported in Kessler et al. (2007) study on the validation of this sixitem screener.

\subsubsection{Control variables}

Demographic variables We included age as a control variable as studies have pointed out that it is an important factor for determining a person's propensity to found a firm (Levesque and Minniti 2006). Age was asked in the following categories: "Less than 25 years old" $(N=14)$, "from 26 to 30 " $(N=121)$, "from 31 to 35 " $(N=68)$, "from 36 to 40 " $(N=75)$, "from 41 to 45 " $(N=82)$, "from 46 to 50 " $(N=64)$, "from 51 to 55 " $(N=52)$, "from 56 to 60 " $(N=23)$, "from 61 to 65 " $(N=20)$, "from 66 to 70 " $(N=15)$, "from 71 to 75 " $(N=0)$, "from 76 to 80 " $(N=0)$, "More than 81 years old" $(N=0)$. Similarly, education has also been associated with entrepreneurship (Dickson et al. 2008) and was thus included in our analysis. Education was measured by the highest level of education accomplished at the time of the questionnaire as follows: $1=$ high school level and less $(N=0), 2=$ undergraduate level $(N=12)$, $3=$ graduate level $(N=187), 4=\mathrm{PhD}$ level $(N=335)$.

Perceived skills and abilities Based on the relation between entrepreneurial self-efficacy and entrepreneurial behavior (Rauch and Frese 2007), and the close connection between entrepreneurial self-efficacy and entrepreneurial skills and ability, we also controlled for these skills and abilities. This was measured in four categories: (1) leadership and communication skills ("You have a personal charisma which can convince people without offending them," "You have the ability to use your instinct in order to evaluate a situation or an issue," "You are capable of spurring, coordinating and synthesizing the work of a group," "You can be available and receptive to others," and "You are capable of taking into account different opinions and harmonize them for general interest"); (2) networking and making professional contacts ("I feel at ease with all type of persons," "when I have an important investment or purchase to do, I know who to talk to," and "I trust others easily"); (3) competitiveness and prestige ("You usually look for a job in which you can improve the wellbeing of others," "You usually look for a job in which you may compete with others with the hope to prevail," "You usually look for a job in which you can acquire prestige in your domain," and "You usually look for a job in which you are well paid"); and (4) innovativeness ("Ability to innovate and identify new issues"). These 12 items were averaged to form an overall measure of perceived skills and abilities. The reliability of this scale, measured by Cronbach's alpha, is .77.

\subsection{Analysis}

To test Hypothesis 1 and 2, linear regressions for both academic entrepreneurial commercialization and personal attitude towards entrepreneurship were performed in two ways: one without control variables and one with control variables. We used ordinal least square (OLS) to estimate the coefficients of these regressions. All variables were standardized for ease of interpretation.

\section{Results}

Table 1 shows the means, standard deviations (SDs), correlations, and Cronbach's alpha (on the diagonal of the correlation matrix) of the main variables.

Table 1 Descriptive statistics $(N=534)$. Means, standard deviations (SDs), correlations, and Cronbach's alpha (diagonal) are displayed

\begin{tabular}{|c|c|c|c|c|c|c|c|c|c|}
\hline & Mean & SD & 1 & 2 & 3 & 4 & 5 & 6 & 7 \\
\hline 1. Academic entrepreneurial commercialization & 2.21 & 1.02 & & & & & & & \\
\hline 2. Personal attitude towards entrepreneurship & 52.73 & 15.50 & $0.20 * * *$ & & & & & & \\
\hline 3. Attention-deficit & 2.36 & 0.60 & $-0.10^{*}$ & $-0.21 * * *$ & 0.64 & & & & \\
\hline 4. Hyperactivity & 2.65 & 0.91 & 0.01 & $-0.10 *$ & $0.28 * * *$ & 0.50 & & & \\
\hline 5. Age & 4.55 & 2.26 & $-0.16^{* * *}$ & 0.04 & 0.04 & $-0.15^{* * *}$ & & & \\
\hline 6. Education & 3.60 & 0.53 & -0.04 & $-0.20 * * *$ & 0.05 & 0.08 & $0.16^{* * *}$ & & \\
\hline 7. Perceived skills and abilities & 65.87 & 12.55 & $0.20 * * *$ & $0.22 * * *$ & $-0.27 * * *$ & 0.00 & $-0.11 *$ & -0.04 & 0.77 \\
\hline
\end{tabular}

$* p<.05 ; * * p<.01 ; * * * p<.001$ 
Correlations range from - .26 to .29 . Note that, as may be expected, the correlation between the two dependent variables academic entrepreneurial commercialization and personal attitude towards entrepreneurship was significantly positive $(r=.20, p<.001)$. In addition, the correlation between attention-deficit symptoms and hyperactivity symptoms was significantly positive $(r=.28, p<.001)$. To test for common method bias (CMB), we applied Harman's single factor test, where a single unrotated principal component should not explain more than $50 \%$ of the variance (Podsakoff et al. 2003). The first principal component in our data explained $16.2 \%$ of the variance, indicating that CMB is unlikely to be of a major concern.

Table 2 shows the OLS regression results. ${ }^{5}$ With respect to academic entrepreneurial commercialization, no significant associations for attention-deficit or hyperactivity were found in the model that included controls. It is worth noting however that the sign of attentiondeficit was negative but not significant, both with and without controls. With respect to personal attitude towards entrepreneurship, attention-deficit was

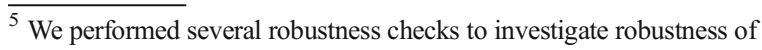
the results. First, we performed the analysis on another group of university employees: administrative and technical personnel $(N=232)$ as this data was also available. Results were similar with respect to personal attitude towards entrepreneurship, although the negative association between attention-deficit and academic entrepreneurial commercialization disappeared for the administrative personnel. The fact that attention-deficit and personal attitude towards entrepreneurship were also negatively associated for the administrative and technical personal could be due to the university environment. Maybe it is not "being academic," but "being in a university environment" that drives the relation between attention-deficit and personal attitude towards entrepreneurship. Second, we split the sample of academic researchers on countries, to investigate the results in France $(N=98)$, Italy $(N=267)$, and Spain $(N=169)$. From these country-level analyses, we found that the main results were mostly driven by the French, followed by Spain and Italy. With respect to Italy, none of the coefficients of interest were significant, while for Spain, attentiondeficit and personal attitude towards entrepreneurship were negatively associated. This negative association was even stronger in the French dataset. In all three analyses, the association between attention-deficit and academic entrepreneurial commercialization disappeared. Finally, we considered a different operationalization of academic entrepreneurial commercialization since items 1 and 2 are about creating a firm, items 3 and 4 about patenting, and item 5 about commercialization by others. We wanted to focus on the more extreme cases explicitly. Therefore, we operationalized the variable as binary, where 1 meant that option (i.e., item) 1 or 2 was chosen and option 5 was not chosen. We performed a logistic regression and found a negative association between attention-deficit and the new operationalization of academic entrepreneurial commercialization in the regression without controls, but this association disappeared in the regression including controls. Thus, the results were similar to our main findings.
}

significantly negatively associated, independent of the inclusion of controls. This confirms our Hypothesis 2. The coefficient estimated in the model with controls was -.142 , which means that an increase of one standard deviation in attention-deficit results in .142 standard deviations decrease in personal attitude towards entrepreneurship, ceteris paribus. Hyperactivity was not associated with personal attitude towards entrepreneurship. In other words, researchers who scored higher on hyperactivity symptoms were not more inclined to commercialize their research results by starting up a firm and/or by patenting. Hypothesis 1 was therefore rejected.

\section{Discussion}

The aim of the present study was to explore academic entrepreneurial preference among academic researchers and connect it to hyperactivity and attention-deficit symptoms. Specifically, we looked at two measures of academic entrepreneurial preference: the willingness to commercialize research results in the form of a firm or by the use of patents, and the personal attitude towards entrepreneurial activities. Our study follows a recent stream of investigations starting from the premise that, while symptoms of ADHD are a liability for wageworkers, they may be positively associated with entrepreneurial intention, orientation, and activities in general. Yet, the association between ADHD symptoms and specific groups in contexts has not yet been explored-a gap that the present study aimed to fill. Building on previous studies that link ADHD symptoms (and more specifically hyperactivity symptoms) to entrepreneurship, and using the theoretical lens of P-E fit, we hypothesized that ADHD symptoms (at the subclinical level) are associated with academic entrepreneurial preference for our specific group of academic researchers. In particular, we hypothesized that hyperactivity symptoms have a positive link with academic entrepreneurial preference while attention-deficit symptoms have a negative link.

The present study contributes to the emergent literature that tries to understand the relationship between mental-health conditions and entrepreneurship (Hatak et al. 2016, 2017) by focusing on ADHD, which is not only a common mental-health condition that affects hundreds of millions of adults worldwide (De Graaf 2008), but also considered as a proof-of-concept 
Table 2 OLS regression results: standardized coefficients with standard errors. $F$-statistics accompanied with $p$ values

\begin{tabular}{|c|c|c|c|c|}
\hline & \multicolumn{2}{|c|}{ Academic entrepreneurial commercialization } & \multicolumn{2}{|c|}{ Personal attitude towards entrepreneurship } \\
\hline & est. & SE & est. & SE \\
\hline \multicolumn{5}{|l|}{ Controls excluded } \\
\hline Attention-deficit & $-0.113^{*}$ & 0.047 & $-0.193 * * *$ & 0.044 \\
\hline Hyperactivity & 0.042 & 0.047 & -0.047 & 0.044 \\
\hline Adj. $R$ squared & 0.007 & & 0.041 & \\
\hline$F$-statistic & 2.958 & 0.053 & 12.423 & 0.000 \\
\hline$N$ & 534 & & 534 & \\
\hline \multicolumn{5}{|l|}{ Controls included } \\
\hline Attention-deficit & -0.046 & 0.048 & $-0.142 * *$ & 0.045 \\
\hline Hyperactivity & 0.003 & 0.047 & -0.031 & 0.044 \\
\hline Age & $-0.134 * *$ & 0.043 & $0.087 *$ & 0.040 \\
\hline Education & -0.011 & 0.070 & $-0.307 * * *$ & 0.066 \\
\hline Perceived skills and abilities & $0.189 *$ & 0.047 & $0.189 * * *$ & 0.044 \\
\hline Adj. $R$ squared & 0.054 & & 0.107 & \\
\hline$F$-statistic & 7.041 & 0.000 & 13.805 & 0.000 \\
\hline$N$ & 534 & & 534 & \\
\hline
\end{tabular}

phenomenon for studies that links mental health with entrepreneurship in general.

Our study, using a sample of 534 academic researchers from three European universities in France, Italy, and Spain reveals that there is no association between hyperactivity and the two measures of academic entrepreneurial preference. In other words, academic researchers who score higher on hyperactivity symptoms do not espouse to be more inclined to commercialize their research results by starting up a firm and/or by patenting; neither do they have a more positive attitude towards entrepreneurial activities as compared to those who do not score high on hyperactivity symptoms. This finding does not support previous research that indicates a link between ADHD and entrepreneurship, and where a positive association was found between hyperactivity and several entrepreneurial outcomes among a sample of students and business owners (Verheul et al. 2015; Wiklund et al. 2016a, b). However, our result showing a negative association between attention-deficit symptoms and personal attitude towards entrepreneurship is in line with that of the Verheul et al. (2016) study.

The absence of a positive association between hyperactivity symptoms and academic entrepreneurial preference among an academic sample could be explained by the theory of P-E fit. An academic environment has similarities with an entrepreneurial environment. Unlike a typical wage-employed environment, the academic environment allows relatively more autonomy, the likelihood to translate hyperactivity into work related actions, and provides more opportunities to express one's creativity. Hence, there may not be any reason for a significant attraction to and preference for entrepreneurship besides the usual research activities. On the other hand, those with a higher incidence of attentional problems may perceive activities beyond their research to be a burden and a further distraction from their focus on current work, which could explain the negative association that we found between attention-deficit and personal attitude towards entrepreneurship. Furthermore, only few adults who experience ADHD symptoms are actually found in higher-ranked occupational positions (i.e., obtain a $\mathrm{PhD}$ degree) due to the negative consequences of their ADHD symptoms (De Graaf 2008). It is likely that those in higher-ranked positions may have found effective ways to cope with their symptoms, which in turn could be due to a good P-E fit (i.e., a fit with the academia).

An alternative explanation for not finding the positive association between hyperactivity symptoms and academic entrepreneurial preference lies in a different interpretation of the theory of P-E fit. It may be the case 
that there simply is no such association in general between ADHD and entrepreneurial preference. One could as well argue that personal traits not only influence one's preference (occupational in this case) but also one's choice of the environment (context). Results of previous studies that show the relation between ADHD and entrepreneurial preference may have been blurred by the heterogeneity of contexts. By restricting our context to the academic environment, the present study corrects for the context heterogeneity.

\section{Limitations and suggestions for future research}

The present study has several limitations. First, both scales for attention-deficit and hyperactivity from the six-item Adult ADHD Self-Report Scale v1.1 (ASRS v1.1) used in this study had a relatively weak reliability as shown by the Cronbach's alpha of .64 and .50, respectively. Nonetheless, these reliabilities are still close to the lower bound of .63 reported in Kessler et al. (2007) validation study of this six-item screener, and reliabilities reported in other studies on ADHD and entrepreneurship (Verheul et al. 2015; Wiklund et al. 2016b).

In the same line, although the null effects suggest that hyperactivity is not related to entrepreneurial preference among researchers, they might also indicate a mismatch between the preference construct we measured and the scales we used, which have not been validated. This emphasizes the explorative nature of the present study. If future studies using validated entrepreneurial preference measures (or closely related measures such as entrepreneurial intention) reach the same conclusions as the present study, it would bolster the claim that hyperactivity is not related to academic entrepreneurial preference.

Second, information on gender, a well-known predictor of entrepreneurial activities (Carter et al. 2003), was not available in our dataset and could therefore not be included as a control variable in the regression. Future studies should try to overcome this limitation. Third, the explained variance of our entrepreneurial preference constructs is low; the antecedents of academic entrepreneurship included in the model of the present study are also not exhaustive.

Due to high prevalence of comorbidity, clinical researchers state that assessment of ADHD is problematic (Jensen et al. 1993). In fact, researchers even assert that distinguishing forms of ADHD by comorbidity, such as grouping people with ADHD into more homogenous groups based on their pattern of comorbidity, is required, for which, methodological innovation is necessary (Biederman et al. 1992; Jensen et al. 1997). Since we used only the ADHD screener, we may well have picked up certain symptoms pertaining to the comorbidities associated with ADHD. Further research needs to take this issue into account.

A possible research avenue could be to investigate the association between attention-deficit/hyperactivity symptoms and actual firm start-up among academic researchers as we expect this relation could be more prominent. Yet another future research avenue worth mentioning is the explicit modeling of the P-E fit mechanism in the relation between ADHD symptoms and different aspects of entrepreneurship. As we have argued above, it is possible that the positive association that has been found in heterogeneous samples could be because this mechanism was not taken into account.

Open Access This article is distributed under the terms of the Creative Commons Attribution 4.0 International License (http:// creativecommons.org/licenses/by/4.0/), which permits unrestricted use, distribution, and reproduction in any medium, provided you give appropriate credit to the original author(s) and the source, provide a link to the Creative Commons license, and indicate if changes were made.

\section{References}

American Psychiatric Association (APA). (2013). Diagnostic and statistical manual of mental disorders (DSM-5). American Psychiatric Publishing.

Anckarsäter, H., Stahlberg, O., Larson, T., Hakansson, C., Jutblad, S. B., Niklasson, L., et al. (2006). The impact of ADHD and autism spectrum disorders on temperament, character, and personality development. American Journal of Psychiatry, 163, 1239-1244.

Antshel, K. M. (2017). Attention deficit / hyperactivity disorder (ADHD) and entrepreneurship. The Academy of Management Perspectives.

Barkley, R. A. (1997). Behavioral inhibition, sustained attention, and executive functions: constructing a unifying theory of ADHD. Psychological Bulletin, 121, 65.

Barkley, R. A., Murphy, K. R., \& Fischer, M. (2010). ADHD in adults: what the science says. New York: Guilford Press.

Baron, R. A. (2008). The role of affect in the entrepreneurial process. Academy of Management Review, 33, 328-340.

Biederman, J., Faraone, S. V., Keenan, K., Benjamin, J., Krifcher, B., More, C., et al. (1992). Further evidence for familygenetic risk factors in attention deficit hyperactivity disorder: patterns of comorbidity in probands and relatives in 
psychiatrically and pediatrically referred samples. Archives of General Psychiatry, 49(9), 728-738.

Biederman, J., Mick, E., \& Faraone, S. V. (2000). Age-dependent decline of symptoms of attention deficit hyperactivity disorder: impact of remission definition and symptom type. American Journal of Psychiatry, 157(5), 816-818.

Biederman, J., Petty, C., Fried, R., Fontanella, J., Doyle, A. E., Seidman, L. J., \& Faraone, S. V. (2006). Impact of psychometrically defined deficits of executive functioning in adults with attention deficit hyperactivity disorders. American Journal of Psychiatry, 163(10), 1730-1738.

Blanchflower, D. G., \& Oswald, A. J. (1998). What makes an entrepreneur? Journal of Labor Economics, 16, 26-60.

Brau, T. (2009). Psychological process of innovative new entrepreneurs: from entrepreneurial involvement to the success of the firm (unpublished doctoral thesis). Caen: University of Caen-Normandy.

Burke, A. E., FitzRoy, F. R., \& Nolan, M. A. (2008). What makes a die-hard entrepreneur? Beyond the 'employee or entrepreneur' dichotomy. Small Business Economics, 31(2), 93-115.

Cable, D. M., \& DeRue, D. S. (2002). The convergent and discriminant validity of subjective fit perceptions. Journal of Applied Psychology, 87(5), 875.

Carter, N. M., Gartner, W. B., Shaver, K. G., \& Gatewood, E. J. (2003). The career reasons of nascent entrepreneurs. Journal of Business Venturing, 18, 13-39.

Cooper, A. C., \& Dunkelberg, W. C. (1986). Entrepreneurship and paths to business ownership. Strategic Management Journal, 7(1), 53-68.

Crea, T., Chan, K., \& Barth, R. (2014). Family environment and attention-deficit/hyperactivity in adopted children: associations with family cohesion and adaptability. Child: Care, Health \& Development, 40, 853-862.

De Graaf, R. (2008). The prevalence and effects of adult attentiondeficit/hyperactivity disorder (ADHD) on the performance of workers: results from the WHO World Mental Health Survey Initiative. Occupational Environmental Medicine, 65, 835842.

Dickson, P. H., Solomon, G. T., \& Weaver, K. M. (2008). Entrepreneurial selection and success: does education matter? Journal of Small Business and Enterprise Development, 15, 239-258.

Edwards, J. R., \& Cooper, C. L. (1990). The person-environment fit approach to stress: recurring problems and some suggested solutions. Journal of Organizational Behavior, 11(4), 293307.

Edwards, J. R., Cable, D. M., Williamson, I. O., Lambert, L. S., \& Shipp, A. J. (2006). The phenomenology of fit: linking the person and environment to the subjective experience of person-environment fit. Journal of Applied Psychology, 91, 802.

Egger, H. L., \& Angold, A. (2006). Common emotional and behavioral disorders in preschool children: presentation, nosology, and epidemiology. Journal of Child Psychology and Psychiatry, 47(3/4), 313-337.

Fayyad, J., De Graaf, R., Kessler, R., Alonso, J., Angermeyer, M., Demyttenaere, K., et al. (2007). Cross-national prevalence and correlates of adult attention-deficit hyperactivity disorder. The British Journal of Psychiatry, 190(5), 402-409.
Frese, M., \& Gielnik, M. M. (2014). The psychology of entrepreneurship. Annual Review of Organizational Psychology and Organizational Behavior, 1, 413-438.

Goethner, M., Obschonka, M., Silbereisen, R. K., \& Cantner, U. (2012). Scientists' transition to academic entrepreneurship: economic and psychological determinants. Journal of Economic Psychology, 33, 628-641.

Gorgievski, M. J., \& Stephan, U. (2016). Advancing the psychology of entrepreneurship: a review of the psychological literature and an introduction. Applied Psychology, 63, 437-468.

Guerrero, M., \& Urbano, D. (2014). Academics' start-up intentions and knowledge filters: an individual perspective of the knowledge spillover theory of entrepreneurship. Small Business Economics, 43(1), 57.

Hatak, I., Wiklund, J., Phan P., \& Dimov, D. (2016). Underdogs, misfits and weirdos: entrepreneurship and mental health. Anaheim, USA: Academy of Management Perspectives Showcase Session, Academy of Management Conference.

Hatak, I., Wiklund, J., Phan P., \& Stephan, U. (2017). ADHD \& entrepreneurship. Atlanta: Academy of Management PDW, Academy of Management Conference.

Hisrich, R., Langan-Fox, J., \& Grant, S. (2007). Entrepreneurship research and practice: a call to action for psychology. American Psychologist, 62(6), 575.

Jensen, P. S., Shervette, R. E., Xenakis, S. N., \& Richters, J. (1993). Anxiety and depressive disorders in attention deficit disorder with hyperactivity: new findings. The American Journal of Psychiatry, 150(8), 1203.

Jensen, P. S., Martin, D., \& Cantwell, D. P. (1997). Comorbidity in ADHD: implications for research, practice, and DSM-V. Journal of the American Academy of Child \& Adolescent Psychiatry, 36(8), 1065-1079.

Johnson, S. L., Freeman, M. A., \& Staudenmaier, P. J. (2015). Manic tendencies are not related to being an entrepreneur, intending to become an entrepreneur, or succeeding as an entrepreneur. Journal of Affective Disorders, 173, 154-158.

Jones-Evans, D. (1992). Technical entrepreneurship in the U.K.: an examination of the relationship between the previous occupational background of the technical entrepreneur and the management of the small technology-based venture. (Unpublished doctoral thesis), Birmingham: Aston University.

Kessler, R. C., Adler, L., Ames, M., Demler, O., Faraone, S., Hiripi, E. V. A., et al. (2005). The World Health Organization Adult ADHD Self-Report Scale (ASRS): a short screening scale for use in the general population. Psychological Medicine, 35(2), 245-256.

Kessler, R. C., Adler, L. A., Gruber, M. J., Sarawate, C. A., Spencer, T., \& Van Brunt, D. L. (2007). Validity of the World Health Organization Adult ADHD Self-Report Scale (ASRS) Screener in a representative sample of health plan members. International Journal of Methods in Psychiatric Research, 16(2), 52-65.

Kessler, R. C., Lane, M., Stang, P. E., \& Van Brunt, D. L. (2009). The prevalence and workplace costs of adult attention deficit hyperactivity disorder in a large manufacturing firm. Psychological Medicine, 39(1), 137-147.

Klofsten, M., \& Jones-Evans, D. (2000). Comparing academic entrepreneurship in Europe-the case of Sweden and Ireland. Small Business Economics, 14(4), 299-309. 
Kristof, A. L. (1996). Person-organization fit: an integrative review of its conceptualizations, measurement and implications. Personnel Psychology, 49(1), -49 .

Kristof-Brown, A. L., Zimmerman, R. D., \& Johnson, E. C. (2005). Consequences of individuals 'fit at work: a metaanalysis of person-job, person-organization, person-group, and person-supervisor fit. Personnel Psychology, 58(2), 281-342.

Lasky, A. K., Weisner, T. S., Jensen, P. S., Hinshaw, S. P., Hechtman, L., Arnold, L. E., Murray, D., \& Swanson, J. M. (2016). ADHD in context: young adults' reports of the impact of occupational environment on the manifestation of ADHD. Social Science and Medicine, 161, 160-168.

Laukkanen, M. (2003). Exploring academic entrepreneurship: drivers and tensions of university-based business. Journal of Small Business and Enterprise Development, 10(4), 372382.

Lerner, D. A., Verheul, I., \& Thurik, R. (2018). Entrepreneurship and attention deficit/hyperactivity disorder: a large-scale study involving the clinical condition of ADHD. Small Business Economics, this issue.

Levesque, M., \& Minniti, M. (2006). The effect of aging on entrepreneurial behavior. Journal of Business Venturing, 21, 177-194.

Llano, J. A. (2010). Determinants of academic entrepreneurship behavior: a multilevel model. Ann Arbor: ProQuest LLC.

Mahone, E. M., Hagelthorn, K. M., Cutting, L. E., Schuerholz, L. J., Pelletier, S. F., Rawlins, C., et al. (2002). Effects of IQ on executive function measures in children with ADHD. Child Neuropsychology, 8(1), 52-65.

Mannuzza, S., Klein, R. G., Bessler, A., Malloy, P., \& LaPadula, M. (1993). Adult outcome of hyperactive boys: educational achievement, occupational rank, and psychiatric status. Archives of General Psychiatry, 50(7), 565-576.

Markman, G. D., \& Baron, R. A. (2003). Person-entrepreneurship fit: why some people are more successful as entrepreneurs than others. Human Resource Management Review, 13(2), 281-301.

Mathieu, C., \& St-Jean, É. (2013). Entrepreneurial personality: the role of narcissism. Personality and Individual Differences, $55(5), 527-531$.

Neider, L. (1987). A preliminary investigation of female entrepreneurs in Florida. Journal of Small Business Management, 25(3), 22.

O'Reilly, C. A., Chatman, J., \& Caldwell, D. F. (1991). People and organization culture: a profile comparison approach to assessing person-organization fit. Academy of Management Journal, 34(3), 487-516.

Parker, S. C. (2009). The economics of entrepreneurship. Cambridge: Cambridge University Press.

Podsakoff, P. M., MacKenzie, S. B., Lee, J. Y., \& Podsakoff, N. P. (2003). Common method biases in behavioral research: a critical review of the literature and recommended remedies. Journal of Applied Psychology, 88, 879-903.

Powers, J. B., \& McDougall, P. P. (2005). University start-up formation and technology licensing with firms that go public: a resource-based view of academic entrepreneurship. Journal of Business Venturing, 20(3), 291-311.

Rauch, A., \& Frese, M. (2007). Let's put the person back into entrepreneurship research: a meta-analysis on the relationship between business owners' personality traits, business creation, and success. European Journal of Work and Organizational Psychology, 16(4), 353-385.

Ripsas, S. (1998). Towards an interdisciplinary theory of entrepreneurship. Small Business Economics, 10(2), 103-115.

Roberts, E. B. (1991). Entrepreneurs in high technology: lessons from MIT and beyond. Oxford: Oxford University Press.

Rosenberg, C. E. (2006). Contested boundaries: psychiatry, disease, and diagnosis. Perspectives in Biology and Medicine, 49, 407-424.

Secnik, K., Swensen, A., \& Lage, M. J. (2005). Comorbidities and costs of adult patients diagnosed with attention-deficit hyperactivity disorder. Pharmaco Economics, 23, 93-102.

Shane, S. (2003). A general theory of entrepreneurship: the individual-opportunity nexus. Aldershot: Edward Elgar.

Shane, S. (2004). Academic entrepreneurship: university spinoffs and wealth creation. New horizons in entrepreneurship series. Aldershot: Edward Elgar.

Shane, S., \& Venkataraman, S. (2000). The promise of entrepreneurship as a field of research. Academy of Management Review, 25(1), 217-226.

The Economist. (2012). In praise of misfits: why business needs people with Asperger's syndrome, attention-deficit disorder and dyslexia. [30-06-2017]. Retrieved from: http://www. economist.com/node/21556230.

Thurik, A. R., Khedhaouria, A., Torrès, O., \& Verheul, I. (2016). ADHD symptoms and entrepreneurial orientation of small firm owners. Applied Psychology, 65(3), 568-586.

Verheul, I., Block, J. H., Burmeister, K., Thurik, A. R., Tiemeier, H. W., \& Turturea, R. (2015). ADHD-like behavior and entrepreneurial intentions. Small Business Economics, 45(1), 85-101.

Verheul, I., Rietdijk, W., Block, J., Franken, I., Larsson, H., \& Thurik, R. (2016). The association between attention-deficit/ hyperactivity (ADHD) symptoms and self-employment. European Journal of Epidemiology, 31, 793.

Vincett, P. (2010). The economic impacts of academic spin-off companies, and their implications for public policy. Research Policy, 39(6), 736-747.

Wiklund, J., Patzelt, H., \& Dimov, D. (2016a). Entrepreneurship and psychological disorders: how ADHD can be productively harnessed. Journal of Business Venturing Insights, 6, 14 20.

Wiklund, J., Yu, W., Tucker, R. L., \& Marino, L. (2016b). ADHD, impulsivity and entrepreneurship. Academy of Management Proceedings, 1, 14003.

Zucker, L. G., Darby, M. R., \& Armstrong, J. S. (2002). Commercializing knowledge: University science, knowledge capture, and firm performance in biotechnology. Management Science, 48(1), 138-153. 